\section{I B R I}

w w w. I ibridergi.org

Kitap Tanıtımı, Eleştiri ve Çeviri Dergisi

Journal of Book Notices, Reviews and Translations

\author{
A. TiMUÇiN, Eskiçağ Ahlakları. İstanbul 2015. Bulut \\ Yayınları, 368 sayfa. ISBN: 9789752865099
}

\title{
Umut ARSLAN
}

OPEN access Journals

Libri: Kitap Tanıtımı, Eleştiri ve Çeviri Dergisi’nde bulunan içeriklerin tümü kullanıcılara açık, serbestçe/ücretsiz "açık erişimli” bir dergidir. Kullanıcılar, yayıncıdan ve yazar(lar)dan izin almaksızın, dergideki kitap tanıtımlarını, eleştirileri ve çevirileri tam metin olarak okuyabilir, indirebilir, dağıtabilir, çıktısını alabilir ve kaynak göstererek bağlantı verebilir.

Libri, uluslararası hakemli elektronik (online) bir dergi olup değerlendirme süreci biten kitap tanıtımları, eleştiriler ve çeviriler derginin web sitesinde (libridergi.org) yıl boyunca ilgili sayının içinde (Sayı III: OcakAralık 2018) yayımlanır. Aralık ayı sonunda ilgili yıla ait sayı tamamlanır. Dergide yayımlanan eserlerin sorumluluğu yazarlarına aittir.

Atıf Düzeni: U. Arslan, Eskiçağ Ahlakları. Yazar: A. Timuçin, Libri IV (2018) 29-37. DOI: $10.20480 /$ lbr.2018007

Geliş Tarihi: 07.01.2018 | Kabul Tarihi: 17.01.2018

Elektronik Yayın Tarihi: 25.01.2018

Editörya: Phaselis Research Project

www.libridergi.org 
Geliș Tarihi: 07.01.2018

Kabul Tarihi: 17.01.2018

Elektronik Yayın Tarihi: 25.01.2018
Kitap Tanıtımı, Eleştiri ve Çeviri Dergisi

回 www.libridergi.org

LIBRI IV (2018) 29-37

\section{A. TimUçiN, Eskiçağ Ahlakları. İstanbul 2015. Bulut Yayınları, 368 sayfa. ISBN: 9789752865099}

Umut ARSLAN*

2015 yılında Bulut Yayınları tarafından yayımlanan Eskiçağ Ahlakları başlıklı çalışma Afşar Timuçin tarafından kaleme alınmıştır. Timuçin'in değerlendirmeleriyle Eskiçağ felsefelerine genel bakış sunulmakla birlikte, ahlak özelinde çağın düşünürlerinin öğretilerine odaklanılmaktadır.

Çalışma; Başlarken (9-37), Eski Yunanistan'ın Toplumsal ve Iktisadi Yapısı (39-65), Felsefede IIlk Atılımlar ilk Düşünürler (69-93), Miletos Okulu ve Ephesoslu Herakleitos (93-115), Pythagoras: Sayıların Filozofu (115-131), Elea Okulunun Usçu Bakış Açısı (131-141), Atomcu Kavrayışlar (141-161), Sofistler (161-175), Sokrates 'de Bilgi ve Ahlak Sorunları (175-205), Platon'un Bilgelik Ahlakı (205-225), Aristoteles Felsefesinde Bilgi ve Ahlak Sorunları (225-257), Epikuros'un Maddeci Atomculuğu (257-277), Roma'da Toplumsal ve Siyasal Yaşam (277-293), Stoa Felsefesi (293-321), Paganlıktan Hıristiyanlığa ya da Eskiçağ’ın Sonu (321-337), Bitirirken (337-347) başlıklı bölümlerden oluşmaktadır. Başlarken ve Bitirirken dışındaki bölümleri kendi içinde alt başlıklara ayrılan eser, kaynaklar ve dizin sunumuyla sonlanmaktadır.

Başlarken (9-37), başlığı altında insanın ve değerlerinin tartışması yürütülürken felsefe-ahlak bağı kurulmaktadır. Bu bağın kurulmasına çalışmanın kapsamını belirlemek açııından önem verilmektedir. Yazar, bu aşamada yetkinleşmiş bilincin önemine değinir. Ahlakın, kolaycı, yetkinleşmemiş bilinçler için yasa koyan biçiminin; yaşamın bilgisinin araştırılmasına, tartışmaya ve usun gelişimine engel olacağı ifade edilmektedir. Bu bağlamda bilgelikten ve

* MA., Akdeniz Üniversitesi, Akdeniz Uygarlıkları Araştırma Enstitüsü, Akdeniz Eskiçağ Araştırmaları Anabilim Dalı, Antalya. umutarslan2@gmail.com | • 0000-0002-2645-9333 
düşünceden bağımsız bir ahlak düşünülemeyeceği için, donanımlı bir usla dünyaya bakmanın önemi çalışmanın içeriği doğrultusunda irdelenmektedir.

Birinci Bölüm: Eski Yunanistan'ın Toplumsal ve Iktisadi Yapısı (39-65) dört alt başlıktan oluşmaktadır. Yunanistan ilk Uygarlıkların Kalıţ̧ısı (39-47) isimli başıkta Hellenlerin nereden geldikleri, kim oldukları ilgili kaynak sunumlarıyla birlikte incelenir. Dor göçleri öncesi Akha toplumu hakkındaki bilgilerle birlikte, Dor göçleriyle başlayan kargaşa dönemi ve yeniden yükseliş döneminde yaşanan gelişmeler sunulmaktadır. Yunan Toplumlarının Yapısı (4755) başlığında kent devletlerinin siyasi, kültürel yaşamı, Atina ve Sparta örnekleri üzerinden antik ve modern kaynaklar da kullanılarak detaylandırılmaktadır. Atina'da yaşanan iktisadi gelişmeler sonucu toplumsal yaşamın iyiden iyiye karmaşıklaşması, yaşanan sınıfsal çelişkilerin yeni siyasi sonuçları olan demokrasi ve tiranlık rejimlerine değinilmektedir. Dış Tehlikeler/Pers Yayılması (55-63) başlıklı bölümde Hellen-Pers savaşlarının geçtiği dönem konu edilmektedir. Hellenler tarafından Pers tehlikesine karşı Attika-Delos Deniz Birliği'nin kurulması ve sonraki yıllarda yaşanan Peleponessos Savaşları incelenir. Makedonya'nın Artan Gücü (63-69) başlığı yazarın ifadesiyle; Hellenlik döneminin bitip, Hellencilik döneminin başlamasına vesile olan, Makedonya'nın Hellas üzerinde baskısının arttığı dönemdeki gelişmeleri ele almaktadır. II Philippos ve Büyük İskender dönemi siyasi gelişmeleriyle birlikte İskender'in hayatı hakkında bilgiler verilmektedir.

Ikinci Bölüm: Felsefede IIlk Atılımlar IIlk Düşünürler (69-93) ana başlığında felsefi düşünüşün ortaya çıkış nedenleri irdelenmekte ve Yedi Bilgeler olarak anılan ilk düşünürler incelenmektedir. Bölüm on alt başlıktan oluşmaktadır. Felsefenin Başlangıç Koşulları (69-72) başlığında, mitolojik düşünceden felsefi düşünceye geçişin toplumsal, coğrafi nedenleri irdelenirken, bu sürecin bazı kültür tarihçileri tarafından mucize olarak ifade edilmesi eleştirilmektedir. Bir diğer başlık Yedi Bilgeler'in (72-74) kim olduklarını ve haklarındaki bilgileri temin ettiğimiz kaynakları açıklamaktadır. Felsefe - mitolojik düşünce ilişkisine değinilmekte ve yedi bilgein felsefeyle bağı incelenmektedir. Diğer alt başlıklar; Kleobulos (74-76), Solon (76-78), Khilon (78-80), Pittakos (80-81), Thales (81-86), Bias (86-87) Anakharsis, Myson, Pherekydes (8993) düşünürlerinin ismini taşımaktadır. Yaşamları hakkında kısa bilgiler içermekle birlikte Diogenes Laertios'un sunduğu kaynaklar doğrultusunda, düşünürlerin mektuplaşmaları, haklarındaki söylenceler, mitlerle karışmış açıkla- 
malar ve özdeyişleri yer almaktadır. Bahsi geçen düşünürler arasından SoIon'un Atina'da uyguladığı reformlara, Kleobulos'un Hellen düşüncesinin orta yer anlayışını dile getiren "Ölçü en iyi şeydir" değimine ve Thales'in bu düşünürler arasından bilgi problemi çerçevesinde ayrılarak evrene, doğaya yönelmesi sonucu gerçek anlamda felsefenin kurucusu olduğuna vurgu yapılması dikkat çekmektedir.

Üçüncü Bölüm: Miletos Okulu ve Ephesos/u Herakleitos (93-115), dört alt başlıktan oluşmaktadır. Ionia'da Büyük Uyanış (93-96) alt başlığı, felsefenin Ionia halklarının yaratısı olduğunu vurgulamaktadır. Ionia üzerindeki doğu etkilerinin felsefenin doğuşuna katkısı ve Miletos kentinin gelişmiş kültürel yaşamının etkileri açıklanmaktadır. Thales, Anaksimandros, Anaksimenes (9699) başlığında Thales'in ve öğrencilerinin felsefelerindeki varlı̆̆ı açıklama çalışmalarına ve belirlemeye çalıştıkları ilksel nedenlere odaklanmaktadır. Değişenin ve Değişmeyenin Filozofu: Ephesoslu Herakleitos (99-115) özelinde Herakleitos'un insan ve evrene dair sorunları bütün halinde tartışmaya açmasıyla birlikte ilk köklü ve kapsayıc felsefe olduğu belirtilmektedir. Bu bağlamda Miletos okuluyla ilişkisine de değinilerek incelenmektedir. Yazar değerlendirmesinde Herakleitos'un ahlak öğretisi geliştirmediğini fakat Stoa felsefesine uzanan bir ahlak anlayışının izinin sürülebileceğini ifade ederek, bunu açmaktadır. "Sonuçta ortada örnek bir yaşam süren filozof vardır" ifadesi ahlak bağlamı kurulmasını sağlamaktadır. Herakleitos'un ahlak anlayışının izi sürülürken ve bilgi problemine yaklaşımı incelenirken, düşünürün 'Doğa Üzerine' adlı yapıtından özdeyişlerle birlikte, çeşitli kaynaklar sunulmaktadır. Dördüncü Bölüm: Pythagoras Sayıların Filozofu (115-131) iki alt başıktan oluşmaktadır. Pythagorasçılığı Hazırlayan Ortam (115-117) başlığında Pers tehdidinin Ege'de yeşeren felsefeye etkisi açıklanmakta ve değişir-değişmeyen ve ussal-duyulur olan çerçevesinde gelişen lonia düşünce dünyası incelenmektedir. Pythagorasçılık Inanca Dönüşen Felsefe (117-131) özelinde Pythagoras'ın yaşamı ve öğretisini geliştirme aşamaları sunulmaktadır. Doğa, matematik, müzik gibi birçok alanda aktif olan Pythagorasçıların kavrayışları, buluşları açıklanmaktadır. Zamanla Dionysosçu ve Orpheusçu öğelerle ayrılamayacak bir biçimde birleşen Pythagorasçılı̆ın, tarikata dönüşmesindeki aşamalar ve takipçilerinin izlediği bazıları ussal olmayan katı kurallar konu edilmektedir. Açıkça sunulan ahlak kuramı bırakmadıkları ifade edilmekle birlikte, Pythagoras'ın çömezi Lysis'in oluşturduğu düşünülen tartışmalı metinler 'Altın Dizeler'den örneklerle desteklenerek ahlak tutumları çözülmekte ve 
değerlendirilmektedir.

Beşinci Bölüm: Elea Okulunun Usçu Bakış Açısı (131-141), dört alt başlıktan oluşmaktadır. Okulun Kurucusu Ksenophanes (131-134) başlı̆ında, Elea okulunun felsefede başka bir başlangıç noktası olduğu vurgulanır. Kurucu Ksenophanes'in hayatı ve düşünceleri hakkında bir dizi bilgi sunulmaktadır. Ksenophanes'in, Hesiodos ve Homeros'un tanrıları insan biçiminde düşünmüş olmasına karşı sunduğu eleştirisiyle, Heptanrıcılık anlayışına ulaşmış olması ilgi çekmektedir. Ahlak özelinde bir görüş bırakmamış olmasına rağmen yazar, Ksenophanes'in "Her şeyden önce eleştiriye yatkın bilge ahlakıyla insanları dogmacı uykularından uyandırmak istiyordu" ifadesiyle Ksenophanes'in ahlak tutumuna netlik kazandırmaya çalışmaktadır. Elea'lı Parmenides (134-135) bölümünde yazar felsefede öğretilerin Parmenides'e kadar doğanın görünümünden temellendirilmesine karşın, Parmenides ile birlikte ussal felsefenin temellerinin atıldığını belirtmektedir. Bu sürecin ise Platon felsefesini temellendirmesine dikkat çekilmektedir. Elealı Zenon (135-139) başlığında Elea okulunun öğretileri toplanmaktadır. Elealı Zenon'un hayatına dair açıklamalar getirilirken, düşünülür ve duyulur dünya ayrımına değinilmektedir. Herakleitos ve Parmenides felsefesinin iki kutuplu yapısına dikkat çekilir. Bir tarafta deneyci lonia olumculuğu, diğer tarafta ise Parmenides usçuluğu vardır. Elea kutbunun deneyci bakışa karşı gelişen bütün felsefelerin temelinde yer aldığı ifade edilmektedir. Elea'dan Sapma: Melissos (139-141) başlığında, Melissos'un Parmenides'i savunmak isterken Elea'dan sapması üzerine görüşleri açılmaktadır. Altıncı Bölüm: Atomcu Kavrayışlar (141-161) dört alt başııtan oluşmaktadır. Atomculuğa Doğru (141-143) başlığında atomculuğun, Ionia'nın duyumculuğuyla Elea'nın usçuluğunu birleştirirken daha gerçekçi bir görünüm elde ettiği ifadesine açıklık getirilmektedir. Yazar, Eskiçağ atomculuğunu önemli bir başarı olarak niteler. Eskiçağ atomculuğunun gelişimi ve düşünürleri hakkında genel bilgiler verilirken eski ve yeni atomculuk ayrımı yapılmaktadır. Empedokles (143-147) atomculuğa kapı aralayan isim olarak bölümde işlenmektedir. Hayatı ve öğretileri hakkında bilgiler kaynaklarla desteklenerek aktarılırken, kişiliğine de değinilmektedir. Doğu - Batı düşünce geleneklerinin ikisine birden yakınlı̆̆ı nedeniyle ve kendisinden önceki filozofların öğretilerini birleştirme çabasından kaynaklı özgün bir öğreti geliştirmiş olması vurgulanmaktadır. Öğretisinde belirlediği ana maddelerin sevgi, nefret duygularıyla form değiştirmesi onu atomculuğa ve 
doğu düşüncesine yakınlaştıran nedenler olarak sıralanarak, öğretisi açılmaktadır.

Anaksagoras (147-150) isimli başlıkta Anaksagoras'ın yapıtı ve hayatına dair bilgiler kaynaklarla desteklenerek açıklanmaktadır. Düşüncesinin içeriğinde kendisinden önceki bütün felsefelerden izler bulunduğu ve Atina'da felsefenin kökleşmesini sağladığı ifade edilir. Geliştirdiği 'nous' kavramı incelenmektedir. Atomculuk: Leukippos ve Demokritos (150-161) başlığında iki ismin yaşamları hakkında bilgiler verilirken, ikilinin atomculuğun kurucusu oldukları ve düşünceleri arasında belirgin bir fark bulunmadığı belirtilir. Öğretileri bilgi problemi çerçevesinde ele alınmaktadır. Çalışmanın konusu bağlamında fiziksel ve ruhsal durumları mekanik, fizyolojik nedenlerle açıklamaları dikkat çekmektedir. Demokritos'un gelişmiş bir ahlak kuramı olmamasına karşın, çalışmada da yer alan özdeyişlerinde yaşam formülleri vermektedir. Yazar, öğretide hazcılığa doğru sezdiği eğilimi açarken aynı zamanda Demokritos'ta önemli olanı bilgelik olarak belirlemektedir. Yedinci Bölüm: Sofistler (161-175) üç alt başlığa ayrılmaktadır. Yeni Yaşam Koşulları (161-169) Atina'nın MÖ IV. yüzyıldaki siyasi, kültürel yaşamını özetleyerek başlamaktadır. Pers tehdidinin kalkması sonrası teknik alandaki ilerlemeler ve Atina'nın kültür merkezi konumuna gelme aşamaları incelenir. Bu gelişime rağmen felsefenin Sofistlerle beraber tabansız bir kuşkucu bakışa bürünmesine, sığlaşarak güzel söz söyleme uğraşı haline gelmesine ve insanların para karşılığı ders veren bu insanlara yönelimine dikkat çekilerek irdelenir. Yine de yazar bu dönemi tam bir verimsizlik dönemi olarak ele almadan bazı açıklamalar sunmaktadır. Protagoras (169-172) başlığında yazar, erdemin öğretilebilir olduğunu belirten düşünürün (bu bağlamda Sokrates'e yaklaştığı) insanı her şeyin ölçütü olarak ele alan düşüncelerini her gün farklı konuşabilmenin felsefi dayanağı olarak açmaktadır. Bölümde Protagoras'ın Hippokrates ve Sokrates'e sunduğu bazı açıklamalara yer verilmektedir. Gorgias ve Öbürleri (172-175) başlığı altında Gorgias'la birlikte Hippias, Polos, Tharsymakhos, Euthydemos, Dionysodoros ve Prodikos'a genel olarak değinilmektedir. Yazar Sofistlerin döneminin, felsefeye altın çağını yaşatacak düşünürlere geçiş aşaması oluşturduğuna dikkat çekmektedir.

Sekizinci Bölüm: Sokrates'de Bilgi ve Ahlak Sorunları (175-205) üç alt başlıktan oluşmaktadır. Değişik Bir Sofist: Sokrates (175-190) özelinde Sokrates'in yaşamı, kişiliği ve yaşadığı dönemin Atina kenti detaylıca modern ve 
antik kaynaklarla desteklenerek anlatılmaktadır. Birçok kaynaktan yararlanılmış olmakla birlikte, daha çok öğrencisi Platon'un kaynakları üzerinden incelenmektedir. Bilgi Anlayışı (190-198) başlığında Sokrates'in evren sorunlarıyla fazlaca ilgilenmediği ve ahlak araştırmacısı olduğuna dikkat çekilir. Öğretisi kullandığı yöntem bağlamında detaylıca ele alınıp tartışımaktadır. Hazların yaşama yön vermesine karşı çıkan, doğru ve düzenli düşünerek bilincin geliştirilmesi gerektiğini ifade eden, insanları düşünmeye ve bilgiye yönlendirmeye çalışan, ölüme giderken bile düşünceleriyle örnek bir filozof yaşamı sunan yapısına dikkat çekilerek, inceleme ahlak bağlamında derinleştirilmektedir. Sokrates'in ahlakın temeline bilgiyi koyduğu ifadesi düşünürün probleme bakışını özetlemektedir. Sokratesçi Okullar (198-203) Kyrene, Kinikler, Megara, Elis ve Eretria ele alınmaktadır. Okullar yer yer Sokrates'in öğretileri kapsamında incelenmektedir. Kiniklerin köleliği, toplumsal ayrıcalıkları, zenginliği ve hazları erdem karşıtı ele alan tutumlarının incelemesi ve Kyrene okulunun ise Kiniklerin neredeyse tam karşıtı hazcı öğretiler geliştirerek Epikuros hazcılığına kapı açması konu bağlamında dikkat çekmektedir. Dokuzuncu Bölüm: Platon'un Bilgelik Ahlakı (205-225) iki alt başlıktan oluşmaktadır. Platon'un Ülkücü Dünyası (205-214) başlığında Platon'un hayatı hakkında bilgiler verilmekte ve eserleri kullandığı yöntem bağlamında incelenmektedir. Platon’u tüm zamanların en iyi filozofu gösterenlere karşı eleştiriler yürütülmüştür. Platon öğretisinin doğal olarak kendisinden önceki felsefelerden etkilendiği belirtilmekle beraber, Herakleitos öğretisiyle Parmenides öğretisini bütünlemeye çalışmasına dikkat çekilerek, inceleme bilgi kuramı bağlamında derinleştirilmektedir.

Ahlak Anlayışı (214-225) başlı̆ında Platon'un bilgi kuramına sıkıca bağlı bir ahlak anlayışı geliştirdiği ifade edilir. Toplumsallıktan bağımsız bir bireysel ahlakın olamayacağına dikkat çekilerek bu bağlamda Platon'un toplum ahlakı, inşası üzerine olan düşünceleri açılmaktadır. Platon'un “Bireysel olarak hazzın, tenin kıskacından kurtulamayan birey erdemi, mutluluğu elde edemez", "Mutluluk insanın en büyük amacıdır" ifadeleri düşünürün ahlak problemine bakışını temellendirmektedir ve bu görüşleri konu bağlamında yaşadığı dönemin dinamikleri de göz önünde bulundurularak değerlendirilmektedir. Onuncu Bölüm: Aristoteles Felsefesinde Bilgi ve Ahlak Sorunları (225-257) dört alt başlıktan oluşmaktadır. Illk başlık Atina'da Bir Yabancı (225-229) kapsamında Aristoteles'in yaşamı, kurduğu okul ve yapıtları hakkında bilgiler 
sunulmaktadır. Aristoteles Felsefesinin Ana Çizgileri (229-235) olarak isimlendirilen başlıkta, düşünürün bilgi ve varlık kuramı açıklanmakta ve hocası Platon hakkındaki eleştirilerine değinilmektedir. Aristoteles Ahlakı (235-246) başlığında Aristoteles'in de her büyük filozofta olduğu gibi ahlak kuramını bilgi kuramı üzerinden kurduğu belirtilmektedir. Düşünürün 'Ethika Nikomakheia' adlı eserine odaklanılarak ahlak kuramı incelenmekte ve Platon'da olduğu gibi amaç mutluluğa ve iyiye yönelmektir ifadesiyle özetlenen kuramı açılmaktadır. Toplumsal Ahlak (246-257) başlığında düşünürün dostluk, adalet, aile, devlet ve iktidar kavramlarına bakışı incelenmektedir. Bu başlıktaki incelemeler için düşürün 'Politika' kitabı kaynak alınmaktadır. On Birinci Bölüm: Epikuros'un Maddeci Atomculuğu'nu (257-277) oluşturan üç alt başlıktan ilki Epikuros'u Hazırlayan Anlayışlar/Pyrrhon ve Öbür Kuşkucular'da (257261) Pyyrhon'un yaşamı hakkında kısa bir sunumun ardından, şeylerin doğasının bilinemez olduğuna dair kuramına açıklık getirilmektedir. Başlık altında ismi geçen diğer düşünürler Arkesilaos, Karneades ve Enesidemes hakkında kısa bilgiler sunulmaktadır. Mutluluğun yolunu, geliştirdikleri kuram doğrultusunda aramaları ve bu yolda çileci, ölüme aldırmadan yaşadıklarının bilgisi dikkat çekmektedir. Epikuros ve Epikurosçuluk (261-271) başlığında Epikurosçuluk Roma'nın kültür dünyasının iki yüzünden biri olarak açıklanmaktadır. Epikuros'un yaşamı hakkında bir dizi bilgi ve Paul Nizan'ın düşünür hakkındaki yazdıkları kaynak olarak sunulmaktadır. Düşünürün 'Klinamen IIlkesi' ve ölüm hakkında Menekles'e yazdığı mektup dikkat çekmektedir. Epikuros'un atom kavrayışının, Demokritos'un atomculuğundan ayrıldığı noktalar karşılaştırılarak incelenmektedir.

Hazlar Ahlakı (271-277) başlığında geçen ahlak anlayışında 'haz' amaç olarak sunulmaktadır. Yazar burada hazzın yanlış anlaşıımasına müsaade etmek istemez ve şöyle yazmaktadır; "Epikuros'u bir zevk sefa filozofu olarak görmeye çalışanlar oldu. Gerçek haz hangi çeşitten olursa olsun bilgelerin hazzıdır. Kendini kapıp koyvermişlerin yaşamı bize hazdan çok daha başka bir şeyleri, örneğin devinim içinde yitirilmiş sevinçleri duyurur". Bu bağlamda Epikuros'un haz yaklaşımı açılmaktadır. Yazar değerlendirmeler yaptığı kısımda Epikuros'un Yeniçağ ve Rönesans'taki etkilerine odaklanmaktadır. On Ikinci Bölüm: Roma'da Toplumsal ve Siyasal Yaşam (277-293) üç alt başlıktan oluşmaktadır. Eski Italya/Etrüskler ve Latinler (277-280) başlığında coğrafya ve iklim hakkında özet bilgiler sunulduktan sonra, Latinlerin ve Etrüsklerin 
yaşam biçimlerine, Roma'nın ilk zamanlarına ve kuruluş efsanelerine değinilmektedir. Roma'da Yaşam (280-285) kapsamında Roma'nın Hellen kültürü etkisi altında dönüşümüyle birlikte askerlik, görenek ve inanç yapılarının incelemesi, kaynak sunumuyla desteklenerek yapılmaktadır. Siyasal ve Toplumsal Oluşumlar (285-293) başlığında cumhuriyetten imparatorluğa geçiş süreci ve imparatorların dönemlerinin kısaca açılmasıyla Roma'nın siyasi tarihi, devlet örgütlenmesi özetlenmektedir. On Üçüncü Bölüm: Stoa Felsefesi (293-321) beş alt başlıktan oluşmaktadır. Uzun Sürmüş Bir Okul Etkinliği (293-297) başlığında okulun gelişimi, öğretiyi geliştiren isimlerin etkinlikleri ve okulun geniş etkisi incelenmektedir. Öğretisi, okulun dönemleri özetlenerek aktarılmaktadır. Imparatorluk Stoa'sı (297-299) dönemi genişletilerek Seneca ve Rufus'un etkinliklerine değinilmektedir. Epiktetos'un (299-302) yaşamı anektdot kullanımıyla zenginleştirilerek anlatılmıştır. Epiktetos'un yöntemine, Hıristiyan ahlakıyla ilişkisinin karşılaştırılmasına da değinilerek yer verilmektedir. Marcus Aurelius (302-306) bölümünde Epiktetos'un yaşamı ve öğretilerinden etkilenen naif, iyi eğitimli, basit yaşamı ilke edinen biri olarak özetlenen Roma imparatoru Aurelius'un, yaşam öyküsü ve Stoa'ya katkıları sunulmaktadır. Stoa Ahlakı (306-321) döneminin düşünürlerinin yazdıklarıyla desteklenerek anlatılmaktadır. İnsancıl, yaşamı ululayan, doğaya uygun olanın peşinde bir yaşam anlayışıyla hareket eden, korkmaktan korkmamanın ilkesinin temel alındığı kuram, yazarın değerlendirmeleriyle birlikte detaylandırılmaktadır.

On Dördüncü Bölüm: Paganlıktan Hristiyanlığa ya da Eskiçağ’ın Sonu (321-337) üç alt başlıktan oluşmaktadır. Yeni Bir Dünya Kurulurken (321-326) başlığında Ortaçağ hakkında genel bir değerlendirme yapılmaktadır. Yeni inanç ve ahlak yapılarının ortaya çıkışı, Pagan değerlerinin Hıristiyan ahlakıyla birlikte dönüşümü eleştirilerek değerlendirilmektedir. İskenderiye kentinin önemi ve Yahudi Philon'un Musa öğretisiyle Platon'u birleştirme çalışması incelenmektedir. Plotinos: Yeni Platonculuk (326-333) Platon'un yeni bir yorumu olarak nitelendirilen kuramda varlık, bilgi ve ahlak kuramı değerlendirilmektedir. Plotinos'un Hıristiyanlığa yakın olmamasına rağmen Hıristiyan felsefesine zemin hazırladığı ifadesi dikkat çekmektedir. Plotinos sonrası dönemi de inceleyen yazar kısaca değindiği isimlerle yeni Platonculuğun geliştirilme çabasını özetlemektedir. Eskiçă̆’ın Ardından (333-337) bölümünde 'kilise babaları' olarak nitelendirilen isimlerin felsefe-Hıristiyanlık bağı kurma çalışmalarına değinilerek dönem hakkında eleştiriler sunulmaktadır. 
Bitirirken (337-347) başlığında yazar ahlak sorunlarının çalışmada ele alınış yöntemine ve nedenine değinmekte, Eskiçağ ahlaklarını özetlerken kendi düşüncelerini ve değerlendirmelerini de sunarak çalışmayı sonlandırmaktadir. 